\title{
Associations among Elder Abuse, Depression and PTSD in South Korean Older Adults
}

\author{
Yun-Jung Choi ${ }^{1, *} \mathbb{C}$, Meaghan $\mathrm{O}^{\prime}$ Donnell ${ }^{2, *}$, Hwa-Bok Choi ${ }^{1}{ }^{\circledR}$, Hae-Sun Jung ${ }^{1}$ \\ and Sean Cowlishaw 2,3 (D) \\ 1 Red Cross College of Nursing, Chung-Ang University, Seoul 06974, Korea; ghkqhr83@naver.com (H.-B.C.); \\ haesun710@hanmail.net (H.-S.J.) \\ 2 Phoenix Australia Centre for Posttraumatic Mental Health, Department of Psychiatry, \\ University of Melbourne, Melbourne, VIC 3053, Australia; sean.cowlishaw@unimelb.edu.au \\ 3 Bristol Medical School, University of Bristol, Bristol BS8 2PS, UK \\ * Correspondence: yunjungchoi@cau.ac.kr (Y.-J.C.); mod@unimelb.edu.au (M.O.); \\ Tel.: +82-2-820-5986 (Y.-J.C.); +61-3-9035-7883 (M.O.)
}

Received: 8 August 2018; Accepted: 4 September 2018; Published: 6 September 2018

\begin{abstract}
Increasing attention is being placed on the prevalence of elder abuse and its impact on mental health. This study conducted a survey of 172 elderly people in South Korea to determine the prevalence of elder abuse and the relationships involving elder abuse, depression and posttraumatic stress disorder (PTSD). Participants completed a battery of self-report questionnaires, which included the Korean Geriatric Depression Screening Scale (KGDS) and Impact of Event Scale-Revised Korean version (IES-R-K). Descriptive analyses were conducted to examine the frequency of specific forms of abuse. Logistic regression models were estimated to identify the factors that contributed to risk of abuse exposure and the relationship between exposure and PTSD or depression. The results indicated around $22 \%$ of the participants reported abuse exposure, which most commonly included being refused physical contact, verbal threats, and/or being excluded from decision-making about personal issues. Low education and being unmarried, separated or divorced was associated with an increased risk of abuse exposure. There were strong associations between elder abuse and PTSD symptoms, while comparable relationships with depression were weaker and were not robust to the inclusion of control variables. The findings provided empirical support for the relationship between abuse experiences of the elderly and poor mental health and raise important issues for the mental health care of the elderly.
\end{abstract}

Keywords: depression; elder abuse; mistreatment; older adults; PTSD; senior citizens

\section{Introduction}

An estimated 5 to $10 \%$ of older people in the United States experience mistreatment each year [1]. In a meta-analysis of data from 59,203 older adults across 44 studies, the mean prevalence rate of elder abuse was $15.7 \%$ [2], with a range between $3.2 \%$ and $27.5 \%$ [3]. Elder abuse is defined as a single or repeated act, occurring within any relationship where there is an expectation of trust, which causes harm or distress to an older person over the age of 65. It includes a range of types of abuse including physical, sexual, emotional and financial abuse, as well as abandonment and neglect [4].

Prevalence rates differ depending on the type of elder abuse. In a South Korean survey of elder abuse among older adults, emotional abuse was highest at $40.1 \%$, followed by physical abuse at $31.3 \%$, neglect at $19.1 \%$, financial abuse at $7.2 \%$, sexual abuse at $1.3 \%$ and abandonment at $1.0 \%$ [5]. Globally, rates of abuse are $11.6 \%$ for psychological abuse, $6.8 \%$ for financial abuse, $4.2 \%$ for neglect, $2.5 \%$ for physical abuse and $0.9 \%$ for sexual abuse [4]. Generally, emotional abuse occurs more frequently than 
physical abuse. In order to minimize elder abuse, South Korea has developed a national institution for the protection of the elderly, which is implementing preventive projects in conjunction with local government. Despite this, the number of reported incidents of elder abuse reports has risen sharply each year, reaching 10,569 in 2014, an increase of 40.8\% over 2010 [5].

Experiences of elder abuse are associated with symptoms of depression [6,7]. Elder abuse survivors with depression are also at increased risk for suicidal thoughts [8]. Posttraumatic stress disorder (PTSD) is a psychiatric disorder featuring symptoms of intrusion, avoidance, negative alterations in cognition and mood and hyper-arousal. Exposure to a traumatic event such as elder abuse may be connected with the development of PTSD [9,10].

Depression and PTSD are often comorbid. Severe depressive symptoms were comorbid with PTSD symptoms in more than one-third of the people who experienced traumatic events [11] and past incidence of depression was strongly associated with probable PTSD [10]. While there have been several studies investigating the relationship between elder abuse and depression [6-8], to date, no study has examined the relationship between elder abuse and PTSD [10].

The broad purposes of this study were to help inform programs for improving the identification and management of depression and PTSD in abused senior citizens. Specific aims of the study were to:

(1) Examine the frequency of specific forms of elder abuse in a community dwelling sample of adults from South Korea;

(2) Identify risk factors for elder abuse; and

(3) Evaluate the mental health implications of elder abuse, with a particular focus on depression and PTSD.

\section{Methods}

\subsection{Participants}

Participants were community-residing adults aged 65 and older who could communicate with the investigator. They were recruited by convenience sampling via advertisements from community academies for the elderly and community mental health improvement centers, located in Seoul and Gyeonggi-Province, South Korea. People were excluded if cognitive function was low, as measured by the MMSE (Mini-Mental State Examination; less than 24 points) [6]. The participants were reimbursed for their participation in the study with grocery items. The criteria for inclusion were the following:

(1) Older adults aged 65 and older who scored more than 24 points on the MMSE.

(2) Older adults who understood the purpose of the study and voluntarily signed the consent form.

(3) Older adults who could read and respond to the self-report questions of the research instruments.

\subsection{Instruments}

\subsubsection{Korean Elder Abuse Scale}

The experience of elder abuse was measured using the assessment tool of the South Korea Elder Protection Agency [5]. The questionnaire contains 20 items which are shown in Table 2 and addresses six domains: (a) physical abuse, (b) emotional abuse, (c) sexual abuse, (d) financial abuse, (e) neglect and (f) abandonment. Each item was scored on a nominal scale, on which participants chose either yes or no based on their lifetime experiences. The Cronbach's alpha for this scale was 0.89 [8].

\subsubsection{Korean Geriatric Depression Screening Scale (KGDS)}

The level of depression in the elderly was evaluated with the KGDS, adapted for South Korean older adults from the GDS [12]. The final version of the KGDS has improved discriminatory diagnostic power, approximately $10 \%$ greater than the GDS, and shows sufficient reliability and validity. The scale consists of 30 items, including 16 negative and 14 positive items. Participants answer yes or no 
depending on their level of depression. The 16 negative items were scored 1 point for yes and 0 points for no and the 14 positive items were scored as 1 point for no and 0 for yes. The total score ranged from 0 to 30. More than 22 points indicates severe depression, while scores of 19 to 21 indicate moderate depression, 14 to 18 indicates mild depression, and scores of 13 or less is considered normal. The Cronbach's alpha for this scale was 0.88 and the split-half reliability was 0.79 [13].

\subsubsection{Impact of Event Scale-Revised Korean Version (IES-R-K)}

The level of PTSD was examined using the IES-R-K, which was modified for Korean people from IES-R [14]. This scale, which is a useful self-rating diagnostic instrument for PTSD symptoms, comprises 22 items [15]. Each item was rated on a Likert scale ranging from 0 to 4 points; higher scores indicate a higher level of PTSD. The total score ranges from 0 to 88 . A score of 25 or more was taken as the cutoff for the high-risk group, 18 to 24 points for the risk group and less than 18 points for the normal group. The split-half reliability for this scale was 0.71 and test-retest reliability was 0.89 [15].

\subsubsection{Demographic Characteristics}

The general characteristics of participants were assessed including gender, age, educational level, family composition and marital status. In addition, the participants' occupation, chronic disease, subjective health and subjective financial status were also assessed.

\subsection{Data Collection}

Data were collected from community academies for the elderly and community mental health improvement centers. The researcher visited each organization in person and conducted a survey of older adults who voluntarily agreed to participate. The researcher filled out the questionnaire instead of the participants when they were physically inconvenienced and asked the agency's staff to participate together in the survey for the protection of the elderly. There were 175 research questionnaires distributed across the four organizations and all were returned; however, 3 were excluded because of incomplete responses and thus a total of 172 were included in the analyses.

\subsection{Ethical Considerations}

All participants voluntarily signed the consent form after the purpose and procedures of the study were explained. Participants were advised that they could withdraw from the survey at any time without disadvantage and that their data would be used only for research purpose. This study received institutional review board approval (No. 1041078-201703-HRSB-047-01).

\subsection{Data Analysis}

Data file preparation was conducted in SPSS version 24, while subsequent analyses were conducted in Program R version 3.4.3. These initially comprised descriptive analyses of items from the Korean Elder Protection Agency Assessment Tool, which were intended to establish the frequency of exposure to specific types of elder abuse. This included an aggregate measure of exposure to any form of abuse, which was treated as a dependent variable in a subsequent series of logistic regression models which examined potential risk factors including socio-demographic characteristics (e.g., gender, age, family composition) and financial or health-related characteristics (e.g., subjectively rated health status, subjectively rated financial status), in order to establish bivariate associations and sub-groups that were distinctively vulnerable to elder abuse. Finally, logistic regression models were also estimated to evaluate the mental health implications of elder abuse. These models specified elder abuse as an explanatory variable and examined associations with mental health outcomes including binary measures of depression (mild/moderate/severe) and PTSD (high risk/risk). Unadjusted models were specified initially to quantify bivariate associations, while adjusted models including additional sociodemographic predictors were presented in order to examine potential confounding from control 
variables. Estimates of the Odds Ratio (OR) and 95\% Confidence Interval (CI) derived from these models were reported as an index of effect size and thus the magnitude of associations. By way of illustration, OR estimates of 4.0 and 5.0, respectively, would suggest that predictor variables are associated with a 4 -fold or 5-fold increase in the odds of the relevant outcome (e.g., elder abuse).

\section{Results}

\subsection{General Characteristics of Participants}

Of the participants, $69.2 \%$ were women and $30.8 \%$ were men. The majority of participants $(56.4 \%)$ were in their $70 \mathrm{~s}$ and $21.5 \%$ were in their $80 \mathrm{~s}$. As for education levels, $36.0 \%$ of the respondents graduated from high school or above and $34.3 \%$ from middle school. A total of $57 \%$ of the participants lived with their spouses, $22.7 \%$ lived with their children and $19.8 \%$ lived alone. A total of $66.3 \%$ of the respondents were married, $24.4 \%$ were widowed and $6 \%$ were unmarried. The majority of the participants were not employed (73.8\%). A total of $57 \%$ of the respondents reported being diagnosed with a chronic disease (Table 1).

Table 1. General characteristics of the participants.

\begin{tabular}{|c|c|c|c|}
\hline Variables & Categories & $n$ & $\%$ \\
\hline \multirow{2}{*}{ Gender } & Male & 53 & 30.8 \\
\hline & Female & 119 & 69.2 \\
\hline \multirow{4}{*}{ Age (year) } & $65 \sim 69$ & 36 & 20.9 \\
\hline & $70 \sim 79$ & 97 & 56.4 \\
\hline & $80 \sim 89$ & 37 & 21.5 \\
\hline & $90 \sim$ & 2 & 1.2 \\
\hline \multirow{4}{*}{ Education level } & Uneducated & 8 & 4.7 \\
\hline & Elementary school & 43 & 25.0 \\
\hline & Middle school & 59 & 34.3 \\
\hline & High school or above & 62 & 36.0 \\
\hline \multirow{4}{*}{ Family composition } & Elderly couples & 98 & 57.0 \\
\hline & Single elderly & 34 & 19.8 \\
\hline & Living with adult children & 39 & 22.7 \\
\hline & Others & 1 & 0.6 \\
\hline \multirow{4}{*}{ Marital status } & Married & 114 & 66.3 \\
\hline & Married (spouse death) & 42 & 24.4 \\
\hline & Married (separation/divorce) & 5 & 2.9 \\
\hline & Unmarried & 11 & 6.4 \\
\hline \multirow{2}{*}{ Employment status } & Yes & 45 & 26.2 \\
\hline & No & 127 & 73.8 \\
\hline \multirow{2}{*}{ Chronic disease } & Yes & 98 & 57.0 \\
\hline & No & 74 & 43.0 \\
\hline \multirow{3}{*}{ Subjective health status } & Good & 45 & 26.2 \\
\hline & Normal & 102 & 59.3 \\
\hline & Poor & 25 & 14.5 \\
\hline \multirow{3}{*}{ Subjective financial status } & Good & 46 & 25.6 \\
\hline & Normal & 114 & 66.3 \\
\hline & Poor & 14 & 8.1 \\
\hline
\end{tabular}

Note: Percentages may not add up to exactly 100 per cent, owing to rounding off.

\subsection{Descriptive Analyses}

Table 2 presents the frequencies of items from the Korean Elder Protection Agency Assessment Tool, which indicates that around $22 \%$ of participants reported any form of elder abuse. The most 
common form of abuse involved emotional abuse, such as being refused physical contact, being subject to verbal threats and being excluded from decision-making about personal issues. Other forms of abuse included violations of their legal rights of personal property and limiting social relations. Theft of income, property and wages were reported less often (by $3-4 \%$ of the sample). There were infrequent reports of various other forms of abuse, including physical or sexual assault and threats of physical harm.

Table 2. Item-level frequencies and proportions with $95 \%$ Confidence Intervals (CIs) for elder abuse indicators.

\begin{tabular}{|c|c|c|c|c|c|}
\hline \multirow{2}{*}{ Domain } & \multirow{2}{*}{ Item } & \multirow[b]{2}{*}{$n$} & \multirow[b]{2}{*}{$\%$} & \multicolumn{2}{|c|}{$95 \%$ CI } \\
\hline & & & & LB & UB \\
\hline \multirow{8}{*}{ Physical abuse } & Physically assaulted & 1 & 0.6 & 0.0 & 3.2 \\
\hline & Forced into confined space and locked in & 0 & 0.0 & - & - \\
\hline & Forced to be physically restrained & 2 & 1.2 & 0.1 & 4.1 \\
\hline & Threatened with a high risk of physical harm & 2 & 1.2 & 0.1 & 4.1 \\
\hline & Subjected to life-threatening physical attacks & 4 & 2.3 & 0.6 & 5.8 \\
\hline & Restricted or hindered by medication & 1 & 0.6 & 0.0 & 3.2 \\
\hline & Forced to do things I did not want or difficult to perform & 1 & 0.6 & 0.0 & 3.2 \\
\hline & Any physical abuse & 5 & 2.9 & 1.0 & 6.7 \\
\hline \multirow{3}{*}{ Sexual abuse } & Sexually abused & 0 & 0.0 & - & - \\
\hline & Received expressions or actions of sexual insult & 3 & 1.7 & 0.4 & 5.0 \\
\hline & Any sexual abuse & 3 & 1.7 & 0.4 & 5.0 \\
\hline \multirow{5}{*}{ Emotional abuse } & Refused physical contact & 17 & 9.9 & 5.9 & 15.4 \\
\hline & Limiting social relations & 6 & 3.5 & 1.3 & 7.4 \\
\hline & Subjected to verbal threats & 9 & 5.2 & 2.4 & 9.7 \\
\hline & Excluded from decision-making about personal issues & 9 & 5.2 & 2.4 & 9.7 \\
\hline & Any emotional abuse & 31 & 18.0 & 12.6 & 24.6 \\
\hline \multirow{4}{*}{ Financial abuse } & Theft of income, property or wages & 6 & 3.5 & 1.3 & 7.4 \\
\hline & Violate the legal rights of personal property & 3 & 1.7 & 0.4 & 5.0 \\
\hline & Not allowed to make decisions about my property use or management & 7 & 4.1 & 1.7 & 8.2 \\
\hline & Any financial abuse & 11 & 6.4 & 3.2 & 11.2 \\
\hline \multirow{4}{*}{ Neglect } & $\begin{array}{l}\text { Have not received basic support for daily living, such as clothes, food, } \\
\text { or housing }\end{array}$ & 4 & 2.3 & 0.6 & 5.8 \\
\hline & Have not received financial support to maintain my basic living & 2 & 1.2 & 0.1 & 4.1 \\
\hline & Have not received medical support though having health problems & 2 & 1.2 & 0.1 & 4.1 \\
\hline & Any neglect & 6 & 3.5 & 1.3 & 7.4 \\
\hline \multirow[t]{2}{*}{ Abandonment } & Told to be sent out from my home & 3 & 1.7 & 0.4 & 5.0 \\
\hline & Any abandonment & 3 & 1.7 & 0.4 & 5.0 \\
\hline Any abuse & & 37 & 21.5 & 15.6 & 28.4 \\
\hline
\end{tabular}

To examine the predictors of abuse, a series of bivariate logistic regression models were conducted (see Table 3). As can be seen, there were no significant associations with elder abuse and age, gender, subjectively rated health or financial status. However, there were significant effects for: (a) education, with participants who completed high school or above indicating reduced risk of abuse, relative to those who completed primary school or less; and (b) marital status, with participants who were unmarried, separated or divorced indicating higher rates of elder abuse, relative to those who were married.

To examine the relationship between any elder abuse and PTSD/depression, further logistic regression models were run (Table 4). These included both unadjusted (bivariate) models, as well as adjusted models which included simultaneous controls for the socio-demographic and subjective measures listed in Table 2. As can be seen, there was significant bivariate associations between elder abuse exposure and depression, which was slightly reduced and non-significant when controlling for other variables. In contrast, the association with elder abuse and PTSD was substantially stronger and was also robust to the inclusion of covariates. Results from the adjusted model indicated that participants reporting any exposure to elder abuse also exhibited a near 5-fold increase in the odds of PTSD scores that were above cut-off criteria. 
Table 3. Frequencies and Odds Ratios (ORs) from bivariate Logistic Regression models predicting any abuse.

\begin{tabular}{|c|c|c|c|c|c|}
\hline \multirow{2}{*}{ Variables } & \multicolumn{2}{|c|}{ Any Abuse } & \multirow{2}{*}{ OR } & \multicolumn{2}{|c|}{$95 \% \mathrm{CI}$} \\
\hline & $n$ & $\%$ & & LB & UB \\
\hline Gender (ref: Female) & 28 & 23.5 & & & \\
\hline Male & 9 & 17.0 & 0.66 & 0.28 & 1.48 \\
\hline Age (ref: 65-69 years) & 6 & 16.7 & & & \\
\hline $70-79$ years & 21 & 21.6 & 1.38 & 0.53 & 4.06 \\
\hline $80+$ years & 10 & 25.6 & 1.72 & 0.57 & 5.64 \\
\hline Education (ref: Elementary school or less) & 16 & 31.4 & & & \\
\hline Middle school & 12 & 20.3 & 0.56 & 0.23 & 1.32 \\
\hline High school or above & 9 & 14.5 & $0.37 *$ & 0.14 & 0.92 \\
\hline Family composition (ref: Couple) & 21 & 21.4 & & & \\
\hline Single & 8 & 23.5 & 1.14 & 0.43 & 2.82 \\
\hline Living with adult children & 8 & 20.5 & 0.96 & 0.37 & 2.33 \\
\hline Marital status (ref: Married) & 22 & 19.3 & & & \\
\hline Widow(er) & 7 & 16.7 & 0.84 & 0.31 & 2.05 \\
\hline Unmarried/separated/divorced & 8 & 50.0 & $4.18^{* *}$ & 1.40 & 12.61 \\
\hline Self-rated health (ref: Normal) & 19 & 18.6 & & & \\
\hline Good & 10 & 22.2 & 1.25 & 0.51 & 2.91 \\
\hline Poor & 8 & 32.0 & 2.06 & 0.75 & 5.38 \\
\hline Chronic disease (ref: Yes) & 16 & 21.6 & & & \\
\hline No & 21 & 21.4 & 1.01 & 0.48 & 2.10 \\
\hline Financial status (ref: Normal) & 19 & 18.6 & & & \\
\hline Good & 10 & 22.2 & 1.39 & 0.59 & 3.14 \\
\hline Poor & 8 & 32.0 & 1.67 & 0.43 & 5.53 \\
\hline
\end{tabular}

Table 4. Descriptive statistics and Odds Ratios (ORs) from Logistic Regression models predicting Depression and Posttraumatic stress disorder (PTSD) categories.

\begin{tabular}{|c|c|c|c|c|c|c|c|c|c|c|}
\hline \multirow{4}{*}{ Outcome } & \multirow{2}{*}{\multicolumn{2}{|c|}{ No Abuse }} & \multirow{2}{*}{\multicolumn{2}{|c|}{ Any Abuse }} & \multicolumn{6}{|c|}{ Logistic Regression Models } \\
\hline & & & & & & adjus & & & djuste & \\
\hline & \multirow{2}{*}{$n$} & \multirow{2}{*}{$\%$} & \multirow{2}{*}{$n$} & \multirow{2}{*}{$\%$} & \multirow{2}{*}{ OR } & \multicolumn{2}{|c|}{$95 \% \mathrm{CI}$} & \multirow{2}{*}{ aOR } & \multicolumn{2}{|c|}{$95 \% \mathrm{CI}$} \\
\hline & & & & & & LB & UB & & LB & UB \\
\hline $\begin{array}{c}\text { Depression } \\
\text { (mild/moderate/severe) }\end{array}$ & 50 & 37.0 & 21 & 56.8 & $2.23 *$ & 1.07 & 4.73 & 1.93 & 0.79 & 4.80 \\
\hline PTSD (moderate/severe) & 38 & 28.1 & 23 & 62.2 & $4.19^{* * *}$ & 1.98 & 9.18 & $4.95^{* * *}$ & 2.13 & 12.10 \\
\hline
\end{tabular}

NB: ${ }^{*} p<0.05,{ }^{* * *} p<0.001$. Adjusted models include gender, age, education, marital status, subjective health and financial status as covariates.

\section{Discussion}

This study investigated the prevalence of elder abuse and its relationship to depression and PTSD. The demographic characteristics of this sample were similar to a national representative survey of South Korean older adults $(n=2362)$ [16], which may speak to the generalizability of the findings in this current study.

Consistent with other South Korean studies [5], emotional abuse was the most common form of abuse reported by older people. This is consistent with a WHO report which also reported the high rates of emotional abuse in elderly people [4]. It may be that interventions designed to educate care givers and support services about what constitutes emotional abuse would help to mitigate this risk.

The current study showed a significant correlation between abuse experience and depression, and thus replicated studies that have also reported relationships between depression and abuse in the 
elderly [6,7]. However, we also extended the findings of other studies by considering the impacts of demographic variables on this relationship. Importantly, we found the relationship between depression and abuse became non-significant when considering the impact of gender, age, education, marital status, subjective health and financial status. While other studies have found a relationship between depression and elder abuse, few have taken into account the impact of demographic characteristics. This suggests the relationship between depression and elder abuse is complex and large, longitudinal studies are required to explore this relationship further.

Previous studies have shown that exposure to trauma increases the risk of PTSD [10]. In this study, there was a strong relationship between elder abuse and PTSD and this relationship remained significant after demographic factors were taken into account. This is an important funding and highlights the need to assess both PTSD symptoms and the potential for elder abuse in older people.

Elder abuse is underrepresented in the scientific literature. Over $20 \%$ of our sample reported experiencing some form of abuse. While acknowledging that the current study was limited in terms of the size and self-selected nature of the sample, it does point to the fact that elder abuse is an important focus for future research. This should investigate the types and frequencies of different types of elder abuse and their impact on mental health. Future research should also focus on the treatment of depression and PTSD after elder abuse.

There current study was characterized by a number of limitations. For example, all measures were based on self-report and do not necessarily indicate diagnoses of major depression or PTSD. The sample size was small and was unable to support complex analyses involving large numbers of explanatory variables. Furthermore, the sample was not derived using systematic sample techniques and is not fully representative of community dwelling older adults in South Korea. This is a cross-sectional study and causation can be inferred but not proven.

\section{Conclusions}

In addition to physical injuries, older adults who are subjected to elder abuse experience emotional difficulties such as depression and PTSD. It is necessary to develop effective abuse management programs that aim to increase understanding of elder abuse and improve strategies for dealing with depression and PTSD in the elderly.

Author Contributions: Y.-J.C. formulated the objectives, designed the methodology and supervised the data assessment. M.O. provided input on the aims of the study and reviewed the manuscript. H.-B.C. and H.-S.J. carried out the data collection. S.C. reviewed the manuscript and contributed to the statistical support. All authors reflected on the results and discussion.

Funding: This research was supported by the National Research Foundation of Korea (NRF) grant funded by the Korea government (MSIP) (No. NRF-2017R1A2B4004438), with additional support from Chung-Ang University Research Grants in 2017.

Conflicts of Interest: The authors declare no conflict of interest.

\section{References}

1. Rosen, T.; Lien, C.; Stern, M.E.; Bloemen, E.M.; Mysliwiec, R.; McCarthy, T.J.; Clark, S.; Mulcare, M.R.; Ribaudo, D.S.; Lachs, M.S.; et al. Emergency medical services perspectives on identifying and reporting victims of elder abuse, neglect and self-neglect. J. Emerg. Med. 2017, 53, 573-582. [CrossRef] [PubMed]

2. Yon, Y.; Mikton, C.R.; Gassoumis, Z.D.; Wilber, K.H. Elder abuse prevalence in community settings: A systematic review and meta-analysis. Lancet Glob. Health 2017, 5, e147-e156. [CrossRef]

3. Cooper, C.; Selwood, A.; Livingston, G. The prevalence of elder abuse and neglect: A systematic review. Age Ageing 2008, 37, 151-160. [CrossRef] [PubMed]

4. World Health Organization. Elder Abuse. Available online: http://www.who.int/news-room/fact-sheets / detail/elder-abuse (accessed on 4 September 2018).

5. Korea Elder Protection Agency. Report on Elder Abuse Status; Korea Elder Protection Agency: Seoul, Korea, 2014. 
6. Roepke-Buehler, S.K.; Simon, M.; Dong, X. Association between depressive symptoms, multiple dimensions of depression and elder abuse: A cross-sectional, population-based analysis of older adults in urban Chicago. J. Aging Health 2015, 27, 1003-1025. [CrossRef] [PubMed]

7. Dong, X. Elder abuse: Systematic review and implications for practice. J. Am. Geriatr. Soc. 2015, 63, 1214-1238. [CrossRef] [PubMed]

8. Seo, I.K.; Lee, Y.S. Mediating effects of self-esteem on the relationship between abuse experience and suicidal ideation of the elderly. Korean J. Gerontol. Soc. Welfare 2016, 71, 219-245.

9. American Psychiatric Association. What Is Posttraumatic Stress Disorder? Available online: https://www. psychiatry.org/patients-families/ptsd/what-is-ptsd. (accessed on 4 September 2018).

10. Palgi, Y. Predictors of the new criteria for probable PTSD among older adults. Psychiatry Res. 2015, 230, 777-782. [CrossRef] [PubMed]

11. Fekih-Romdhane, F.; Chennoufi, L.; Cheour, M. PTSD and depression among museum workers after the March 18 Bardo museum terrorist attack. Community Ment. Health J. 2017, 53, 852-858. [CrossRef] [PubMed]

12. Yesavage, J.A.; Brink, T.L.; Rose, T.L.; Leirer, V.O. Development and validation of geriatric depression screening scale: A preliminary report. J. Psychiatr. Res. 1983, 17, 37-49. [CrossRef]

13. Jung, I.-K.; Kwak, D.-I.; Joe, S.-J.; Lee, H.-S. A study of standardization of Korean Form of Geriatric Depression Scale. J. Korean Geriatr. Psychiatry 1997, 1, 61-72.

14. Horowitz, M.J.; Wilner, N.; Alvarez, W. The impact of event scale: A measure of subjective stress. Psychosom. Med. 1979, 41, 209-218. [CrossRef] [PubMed]

15. Eun, H.-J.; Kwon, T.-W.; Lee, S.-M.; Kim, T.-H.; Choi, M.-R.; Cho, S.J. A study on reliability and validity of the Korean version of Impact of Event Scale-Revised. J. Korean Neuropsychiatr. Assoc. 2005, 44, 303-310.

16. An, J.-Y. Levels of health and subjective life expectancy among community-dwelling elders in Korea. J. Korean Gerontol. Nurs. 2018, 20, 22-34. [CrossRef]

(C) 2018 by the authors. Licensee MDPI, Basel, Switzerland. This article is an open access article distributed under the terms and conditions of the Creative Commons Attribution (CC BY) license (http:/ / creativecommons.org/licenses/by/4.0/). 